\title{
Response surface methodology as a tool to study the lipase-catalyzed synthesis of betulinic acid ester
}

\begin{abstract}
BACKGROUND: The synthesis of betulinic acid ester using betulinic acid and oleyl alcohol catalyzed by Novozym 435 (immobilized Candida antarctica lipase) was carried out. Response surface methodology (RSM) based on a five-level, three-variable, central composite rotatable design (CCRD) was employed to evaluate the interactive effects of various parameters. The parameters were reaction time $(8-16 \mathrm{~h})$, temperature $(20-60 \circ \mathrm{C})$ and enzyme amount (120-160 mg). RESULTS: Simultaneously increasing reaction time, temperature and amount of enzyme increased the yields of betulinic acid ester produced. CONCLUSION: The optimum conditions derived via RSM for the reaction were reaction time of $10.2 \mathrm{~h}$, temperature of $53.1{ }^{\circ} \mathrm{C}$ and enzyme amount of $138 \mathrm{mg}$. The actual experimental yield was $48.5 \%$ under optimum conditions, which compared well with the maximum predicted value of $47.6 \%$.
\end{abstract}

Keyword: betulinic acid ester, enzymatic synthesis, lipase, response surface methodology (RSM) 